\title{
Effect of Axial Compression Ratio on Seismic and Self-Centering Performance of Unbonded Prestressed Concrete Columns
}

\author{
Yun Shi $\mathbb{D}^{1,2}$ Guanglin Yuan, ${ }^{1}$ and Hao $\mathrm{Zhu}^{2}$ \\ ${ }^{1}$ School of Mechanics and Civil Engineering, China University of Mining and Technology, Xuzhou 221008, Jiangsu, China \\ ${ }^{2}$ School of Civil Engineering and Architecture, Suqian University, Suqian 223800, Jiangsu, China \\ Correspondence should be addressed to Yun Shi; sqshiyun@qq.com
}

Received 29 October 2021; Accepted 17 December 2021; Published 18 January 2022

Academic Editor: Wenjie Ge

Copyright (C) 2022 Yun Shi et al. This is an open access article distributed under the Creative Commons Attribution License, which permits unrestricted use, distribution, and reproduction in any medium, provided the original work is properly cited.

\begin{abstract}
To explore the influence of the applied axial compression ratio and preloaded axial compression ratio on the seismic performance of unbonded prestressed concrete columns, pseudo-static tests were carried out on four prestressed columns and one ordinary column in this study. The seismic performance indexes of test columns were studied and analyzed, including failure modes, hysteresis curves, skeleton curves, stiffness, ductility, and energy dissipation. The test results show that compared with concrete columns with ordinary reinforcement, the hysteresis curve of reinforced concrete columns with prestressed tendons has a pinch phenomenon to a certain extent, and the energy dissipation performance becomes worse. For the prestressed columns, the greater the applied axial compression ratio, the worse the fullness of hysteresis curves and the energy dissipation performance, the greater the residual displacement, the faster the strength attenuation, and the worse the self-centering performance. For the posttensioned unbonded prestressed concrete columns, the greater the preloaded axial compression ratio, the worse the energy dissipation performance of the test column, the slower the strength attenuation, and the better the self-centering performance.
\end{abstract}

\section{Introduction}

The previous analysis of earthquake disasters has shown that building structures after the earthquake can produce large residual deformation. Many building structures are not damaged but difficult to repair due to large residual displacement and have to be demolished and rebuilt, resulting in resource waste and property loss [1]. Therefore, the development and research of a building with small residual deformation after an earthquake are an important direction of building development in the future [2-10]. At present, the common methods to improve the self-resetting performance of specimens are adding unbonded prestressed reinforcement, adding viscous damper, setting unbonded highstrength reinforcement, and so on. Unbonded prestressed tendons are widely used because of their advantages of convenient construction and low cost. The existing research has shown that when unbonded prestressed tendons are added to the ordinary reinforced concrete columns for applying the prestress, the high-strength elastic recovery characteristics of prestressed tendons can be used to effectively reduce the residual displacement of structures or members and obtain good self-centering performance.

Roke [11] conducted the time history analysis of three central braced frame structures with different positions of prestressed tendons and found that this structure has a good self-centering effect. Luo Haiyan [12] carried out comparative tests of three concrete columns with unbonded partially prestressed tendons and one concrete column with ordinary reinforcement. It was found that the prestress level has an important influence on the performance of the specimens. Yang Yiming et al. [13] performed pseudo-static tests of two RC frame column base joints equipped with unbonded prestressed tendons and energy dissipation damper. It was reported that the axial compression ratio has an important impact on the seismic performance and selfcentering performance of RC frame column base joints. Through the above research, it can be found that the axial compression ratio is an important factor affecting the seismic and self-centering performance of reinforced 
concrete frame columns. However, there is no research on the specific influence law of the applied axial compression ratio and preloaded axial compression ratio on their performance. In this study, four concrete columns with posttensioned unbonded prestressed tendons and one ordinary reinforced concrete column were designed at a reduced scale of $1 / 2$, and pseudo-static loading tests on these columns were performed to analyze their energy dissipation performance, strength attenuation, and self-centering performance.

\section{Experimental Investigation}

2.1. Description of Specimens. In this test, four concrete columns with posttensioned unbonded prestressed tendons (marked as PURC) and one ordinary reinforced concrete column (marked as PTRC) were designed and fabricated in the proportion of $1 / 2$. The column height was $1200 \mathrm{~mm}$, and the section size was $300 \mathrm{~mm} \times 300 \mathrm{~mm}$. Table 1 and Table 2 show the axial compression ratio of the test piece, and Figure 1 shows the size and reinforcement of the test piece. The C40 concrete was used, and the measured compressive strength of the cube was $44.5 \mathrm{MPa}$. The longitudinal main reinforcement was $\mathrm{HRB} 400$ grade, with a diameter of $20 \mathrm{~mm}$, the measured yield strength of $536.2 \mathrm{MPa}$, elongation of $19 \%$, and elastic modulus of $2.00 \times 10^{5} \mathrm{MPa}$. The stirrup was HPB300 grade, with the measured yield strength of $371.0 \mathrm{MPa}$ and elastic modulus of $2.10 \times 10^{5} \mathrm{MPa}$. In this study, $\zeta=N_{\mathrm{p}} / f_{\mathrm{c}} A$ and $\eta=N / f_{\mathrm{c}} A$, where $\zeta$ is the preloaded axial compression ratio, $\eta$ is the applied axial compression ratio, $N_{\mathrm{p}}$ is the axial pressure exerted by prestressed tendons, $N$ is the applied axial pressure, $f_{\mathrm{c}}$ is the design value of concrete compressive strength, and $A$ is the column section area.

2.2. Prestressed Tendon Tensioning. To exert the prestress, four $\Phi^{\mathrm{S}} 15.2\left(f_{p t k}=1860 \mathrm{~N} \cdot \mathrm{mm}^{-2}\right) 1 \times 7$ steel strands were uniformly arranged at the four corners of the column section during the production of the column specimens. To ensure the flatness of the upper and lower sides of specimens, one end of the prestressed tendons was pretensioned at the column top and embedded in the concrete. The steel strand was covered with a thin steel pipe and fixed at the design position through the perforated steel plate at the column top and the column bottom to avoid the shift of the steel strand during the pouring and vibrating of concrete. To obtain the smooth bottom of test columns for the subsequent test, a groove of $300 \mathrm{~mm} \times 400 \mathrm{~mm} \times 150 \mathrm{~mm}$ was reserved at the bottom of the column during the fabrication for tensioning and anchoring prestressed steel strand, and the single-hole tool anchor was used.

The size of the prestressed members used in this test was smaller than that in the actual project; moreover, the reduction in length can cause a large amount of prestress loss [14]. To solve this problem, a support foot device developed by the China University of Mining and Technology was used to supplement the tension by the insert gasket [15]. Figure 2 shows the specific operation process, and Table 3 shows the detailed tension control stress.
2.3. Loading Device and Loading System. The test was conducted in Jiangsu Key Laboratory Environmental Impact and Structural Safety in Engineering, China University of Mining and Technology. The electrohydraulic servo loading structure test machine was used for pseudo-static loading under low-cycle repeated loading [16]. Figure 3 shows the loading device. The vertical load was applied to the design value through two hydraulic jacks at the top of the column, and the horizontal load was applied by the actuator at the top of the column.

The load-displacement control mode was adopted in the loading process. The loading system was as follows: the yield displacement $\Delta$ of each test column was obtained by the load control with an increase of $10 \mathrm{kN}$. After the test column yielded, the loading was performed according to the controlled displacement of $1 \Delta, 2 \Delta, 3 \Delta$, and so on. Before the test column yielded, load control and displacement control were cycled once; after the test column yielded, displacement control was loaded for three times at each level. When the load dropped below $85 \%$ of the maximum load value, the specimen was considered to be destroyed and the test was terminated.

\section{Experimental Phenomenon and Failure Mode}

Figure 4 shows the final failure modes of test columns. The loading failure process of test columns is described as follows:

(1) Specimen PTRC-1. After formal loading, the test column showed significant elastic characteristics before yielding. When the horizontal force was applied to $56.8 \mathrm{kN}$, the first horizontal crack appeared on the right side of the column $130 \mathrm{~mm}$ from the base. When the controlled displacement was $18 \mathrm{~mm}$, cracks on the front and rear sides extended obliquely and vertically, and multiple through cracks appeared on the left and right sides. The through cracks were clearly observed during the unloading. When the controlled displacement was $27 \mathrm{~mm}$, a small area of damage was generated in the concrete of the column corner, and vertical cracks appeared in the middle of the left and right sides of the column body. The specimen reached the limit state, and the horizontal force had an extreme value $(200.71 \mathrm{kN}$ in the forward direction and $173.20 \mathrm{kN}$ in the reverse direction). When the controlled displacement was $54 \mathrm{~mm}$, the horizontal load dropped below $85 \%$ of the ultimate load value. After the test termination, the failure mode of the test column was mainly the flexural shear failure, showing good ductility characteristics.

(2) Specimen PURC-1. After formal loading, when the load was added to $59.3 \mathrm{kN}$, the first horizontal crack appeared on the right side of the column $75 \mathrm{~mm}$ from the base. When the controlled displacement was $18 \mathrm{~mm}$, vertical cracks were gradually produced in the bottom beam during the first cycle, and the horizontal cracks continued to extend and develop. When the controlled displacement was $27 \mathrm{~mm}$, the 
TABLE 1: Design parameters of specimens.

\begin{tabular}{|c|c|c|c|c|c|c|c|c|c|}
\hline $\begin{array}{l}\text { Specimen } \\
\text { number }\end{array}$ & $\begin{array}{l}\text { Section size } \\
\mathrm{mm} \times \mathrm{mm}\end{array}$ & $\begin{array}{l}\text { Concrete } \\
\text { strength } \\
\text { grade }\end{array}$ & & $\begin{array}{l}\text { ongitudinal } \\
\text { inforcement }\end{array}$ & $\begin{array}{l}\text { Reinforcement } \\
\quad \text { ratio } \rho_{\mathrm{t}} / \%\end{array}$ & $\begin{array}{l}\text { Column } \\
\text { stirrup }\end{array}$ & $\begin{array}{l}\text { Prestressed } \\
\text { tendons }\end{array}$ & $\begin{array}{l}\text { Effective } \\
\text { prestress }\end{array}$ & $\begin{array}{l}\text { Shear } \\
\text { span } \\
\text { ratio } \lambda\end{array}$ \\
\hline PTRC-1 & $300 \times 300$ & $\mathrm{C} 40$ & $\Phi$ & $\begin{array}{c}8 \\
20\end{array}$ & 2.79 & Ф8@50/100 & - & - & 3.5 \\
\hline PURC-1 & $300 \times 300$ & $\mathrm{C} 40$ & $\Phi$ & $\begin{array}{c}8 \\
20\end{array}$ & 2.79 & Ф8@50/100 & $4 \Phi^{\mathrm{S}} 15.2$ & $0.65 f_{\mathrm{ptk}}$ & 3.5 \\
\hline PURC-2 & $300 \times 300$ & $\mathrm{C} 40$ & $\Phi$ & $\begin{array}{c}8 \\
20\end{array}$ & 2.79 & Ф8@50/100 & $4 \Phi^{\mathrm{S}} 15.2$ & $0.65 f_{\mathrm{ptk}}$ & 3.5 \\
\hline PURC-3 & $300 \times 300$ & $\mathrm{C} 40$ & $\Phi$ & $\begin{array}{c}8 \\
20\end{array}$ & 2.79 & Ф8@50/100 & $4 \Phi^{\mathrm{S}} 15.2$ & $0.65 f_{\mathrm{ptk}}$ & 3.5 \\
\hline PURC-4 & $300 \times 300$ & $\mathrm{C} 40$ & $\Phi$ & $\begin{array}{c}8 \\
20 \\
\end{array}$ & 2.79 & Ф8@50/100 & $4 \Phi^{\mathrm{S}} 15.2$ & $0.45 f_{\mathrm{ptk}}$ & 3.5 \\
\hline
\end{tabular}

TABLE 2: Axial compression ratios of specimens.

\begin{tabular}{lcccc}
\hline $\begin{array}{l}\text { Specimen } \\
\text { number }\end{array}$ & $\begin{array}{c}\text { Axial compression ratio } \\
n\end{array}$ & $\begin{array}{c}\text { Preloaded axial compression } \\
\text { ratio } \zeta\end{array}$ & $\begin{array}{c}\text { Applied axial compression } \\
\text { ratio } \eta\end{array}$ & $\begin{array}{c}\text { Applied axial compression } \\
\mathrm{kN}\end{array}$ \\
\hline PTRC-1 & 0.15 & - & 0.15 & 238.05 \\
PURC-1 & 0.55 & 0.40 & 0.15 & 238.05 \\
PURC-2 & 0.45 & 0.40 & 0.05 & 79.35 \\
PURC-3 & 0.65 & 0.40 & 0.25 & 396.75 \\
PURC-4 & 0.40 & 0.25 & 0.15 & 238.05 \\
\hline
\end{tabular}

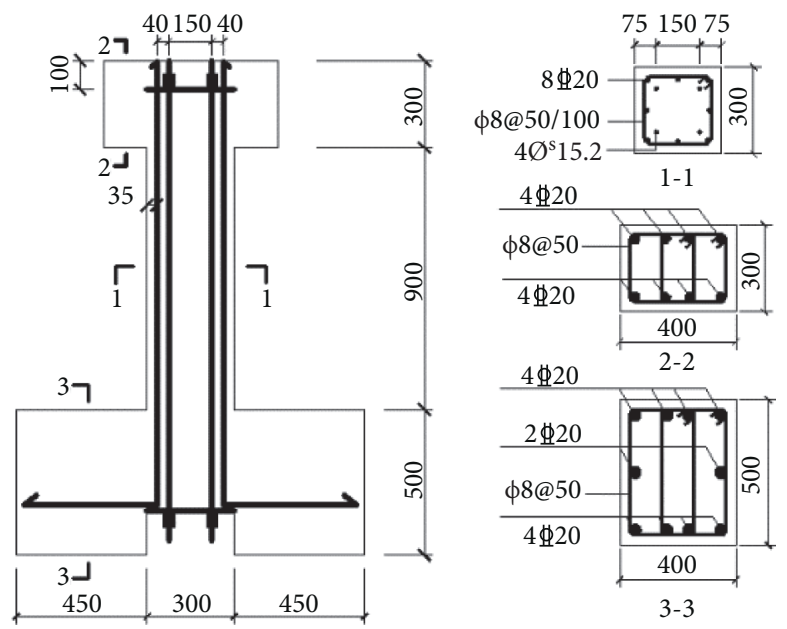

Figure 1: Size and section reinforcement of test columns (mm).

specimen reached the limit state during the first cycle, and the horizontal force had an extreme value $(201.06 \mathrm{kN}$ in the forward direction and $195.19 \mathrm{kN}$ in the reverse direction). When the controlled displacement was $54 \mathrm{~mm}$, the horizontal load of the test column dropped below $85 \%$ of the ultimate load, and the test was terminated.

(3) Specimen PURC-2. After formal loading, when the load was increased to $53.2 \mathrm{kN}$, the first horizontal crack was produced at the connection between the column body and the base. When the controlled displacement was $\pm 27 \mathrm{~mm}$, the cracks on the column body were widened and the four cracks extended vertically. During the cycle under the controlled displacement of $30 \mathrm{~mm}$, new cracks were no longer generated and the load peak appeared $(198.50 \mathrm{kN}$ in the forward direction and $203.57 \mathrm{kN}$ in the reverse direction). When the controlled displacement was $60 \mathrm{~mm}$, the horizontal load of the test column dropped below $85 \%$ of the ultimate load, and the test was terminated.

(4) Specimen PURC-3. After formal loading, when the load was added to $76.4 \mathrm{kN}$, multiple horizontal cracks were generated on the right side of the column $50 \mathrm{~mm}, 150 \mathrm{~mm}, 250 \mathrm{~mm}$, and $375 \mathrm{~mm}$ away from the base. When the controlled displacement was $\pm 24 \mathrm{~mm}$, the vertical crack perpendicular to the horizontal crack began to appear. When the controlled 


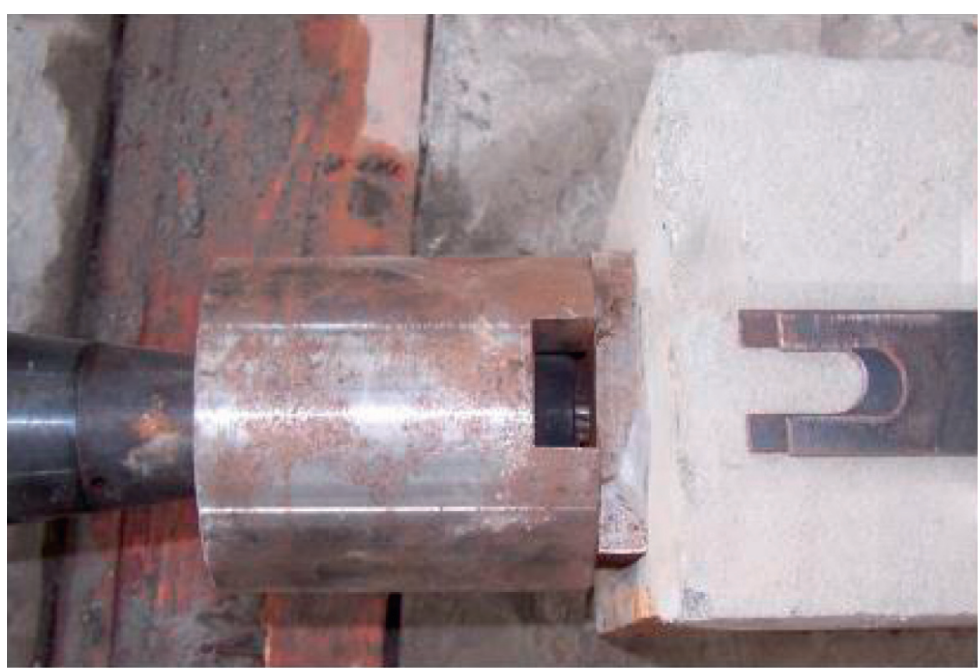

(a)

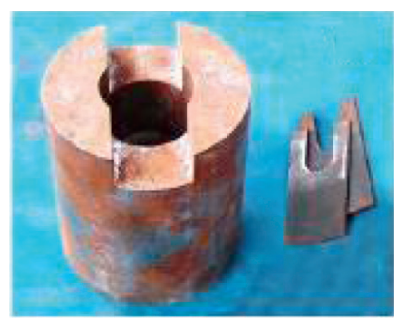

(b)

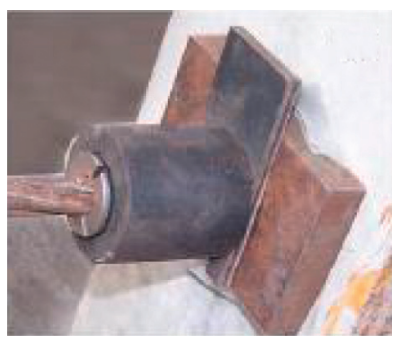

(c)

Figure 2: Insert gasket for tension supplement. (a) Insert gasket for tension supplement and (b) brace angle and gasket (c) after tension supplement [15].

TABLE 3: Tensioning data of prestressed tendons.

\begin{tabular}{|c|c|c|c|c|c|}
\hline Specimen No. & PTRC-1 & PURC-1 & PURC-2 & PURC-3 & PURC-4 \\
\hline Prestress loss $/\left(N \cdot \mathrm{mm}^{-2}\right)$ & - & 60.06 & 60.06 & 60.06 & 50.82 \\
\hline Tension control force/ $\mathrm{kN}$ & - & 176.40 & 176.40 & 176.40 & 149.26 \\
\hline
\end{tabular}

displacement was $\pm 32 \mathrm{~mm}$, the specimen reached the limit state during the first cycle, and the extreme value of the horizontal force was obtained $(211.16 \mathrm{kN}$ in the forward direction and $209.83 \mathrm{kN}$ in the reverse direction). After that, the bearing capacity decreased continuously with the failure of the specimen. When the controlled displacement was $48 \mathrm{~mm}$, the horizontal load of the test column dropped below $85 \%$ of the ultimate load, and the test was ended.

(5) Specimen PURC-4. After formal loading, when the load was $59.3 \mathrm{kN}$, the first horizontal crack appeared on the right cylindrical surface $160 \mathrm{~mm}$ away from the base. When the controlled displacement was $27 \mathrm{~mm}$, the new cracks were not generated. During the first loading of $0 \longrightarrow 27 \mathrm{~mm}$, the load peak appeared $(192.14 \mathrm{kN}$ in the forward direction and $192.46 \mathrm{kN}$ in the reverse direction), the concrete at the column corner of the left foot began to crush, the cracks developed vertically, and a main vertical crack was formed in the middle of the left and right sides. When the controlled displacement was $54 \mathrm{~mm}$, the horizontal load of the test column dropped below $85 \%$ of the ultimate load, and the test was ended.

\section{Experimental Results and Discussion}

4.1. Hysteresis Curves. The hysteresis curves of different specimens are compared (Figure 5). It can be seen that:

(1) At the initial stage of loading, the hysteresis curve of each specimen approximates a straight line, indicating that the specimen is in the elastic stage at this time. With the increase in load and displacement, the area of the hysteresis loop increases continuously, and the hysteresis curve no longer grows as a straight line. It indicates that the specimen enters the elasticplastic stage. After unloading, the residual displacement increases, the plastic damage develops, and the energy dissipation performance is improved.

(2) Hysteresis curves of PURC-1-PURC-4 and PTRC-1 are compared. It can be found that there is an obvious pinch phenomenon in hysteresis curves of 

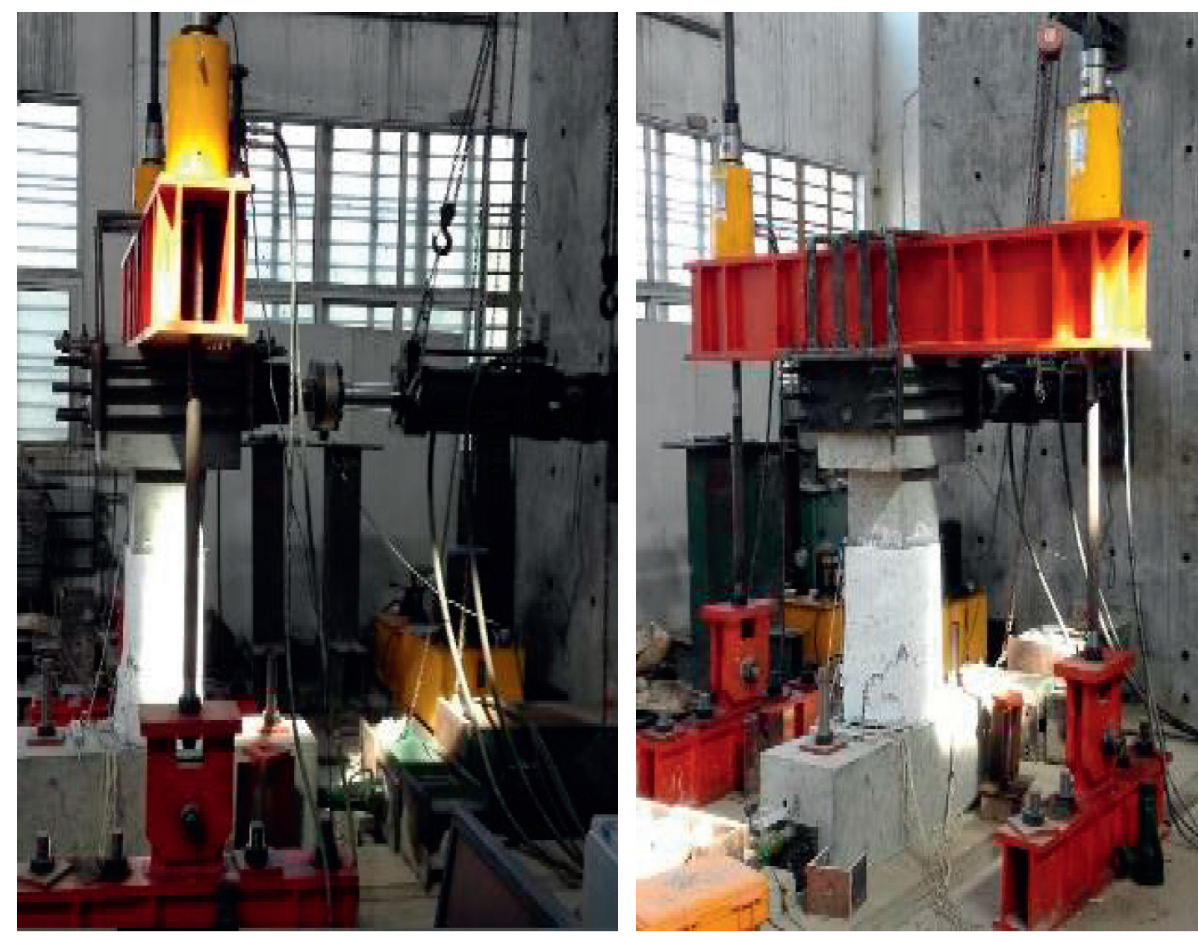

Figure 3: Test loading device.

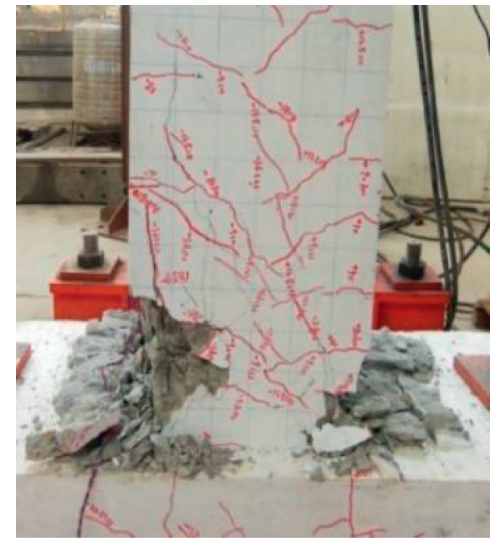

(a)

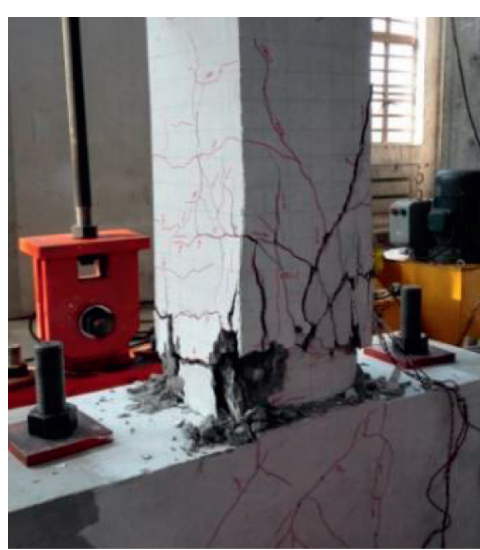

(d)

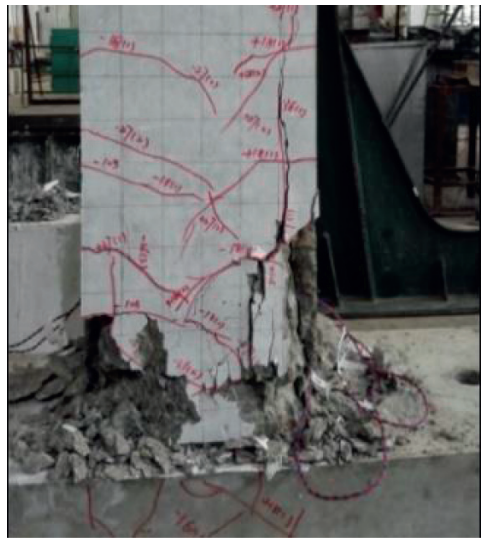

(b)

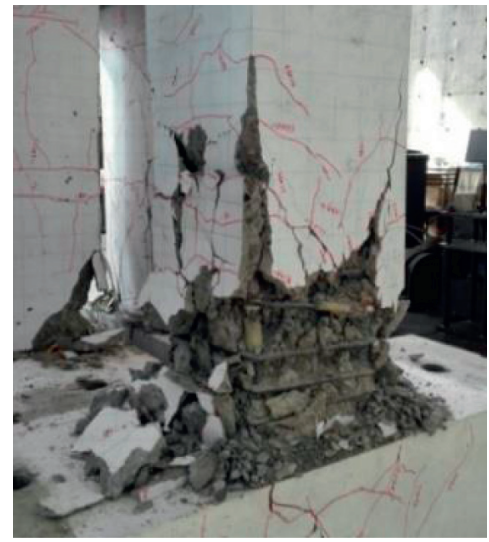

(c)

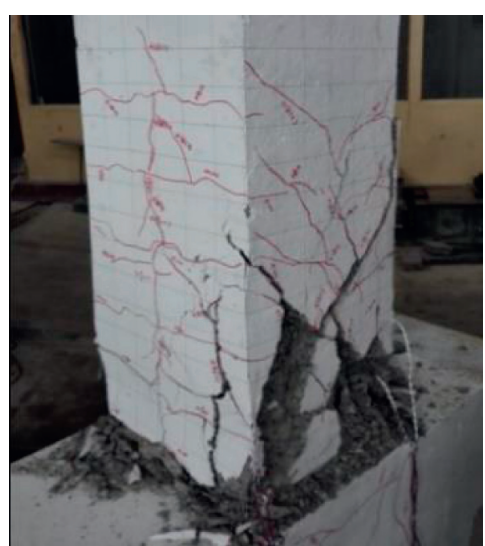

(e)

Figure 4: Failure modes of specimens. (a) PTRC-1. (b) PURC-1. (c) PURC-2. (d) PURC-3. (e) PURC-4. 


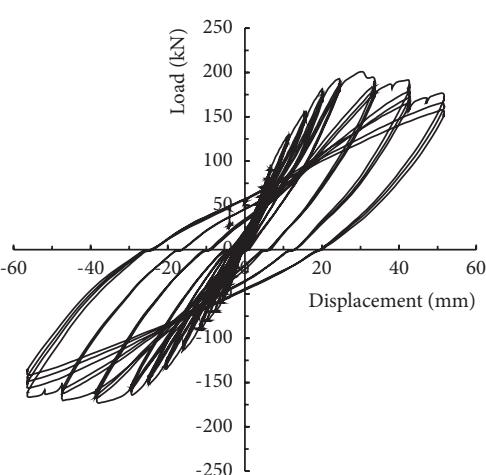

(a)

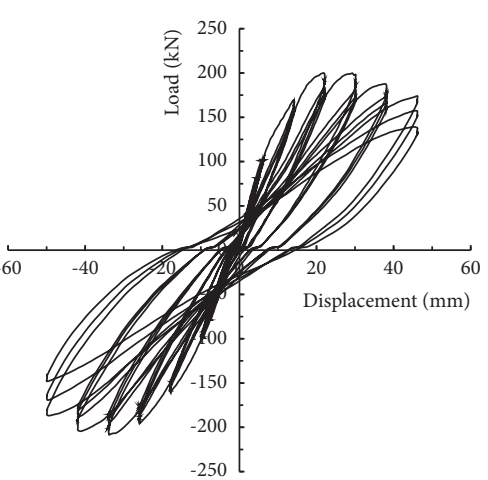

(d)

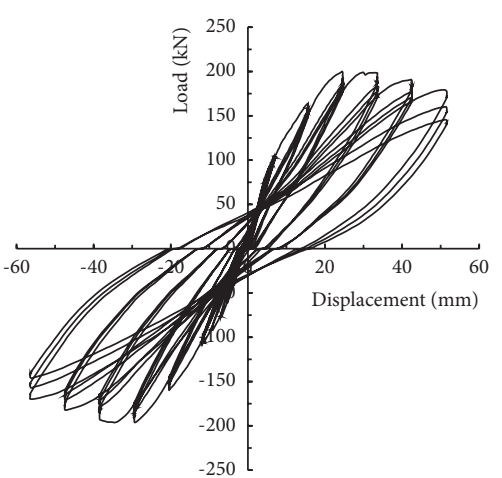

(b)

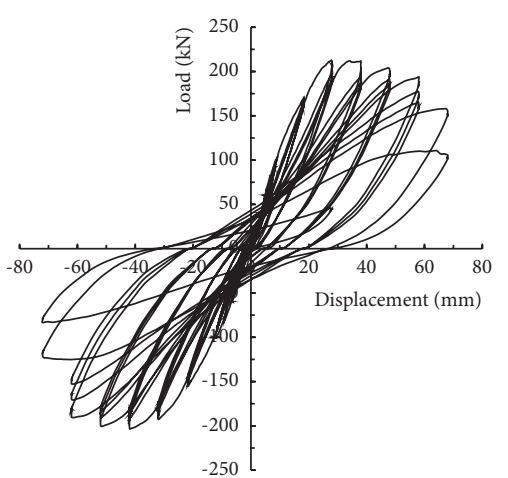

(c)

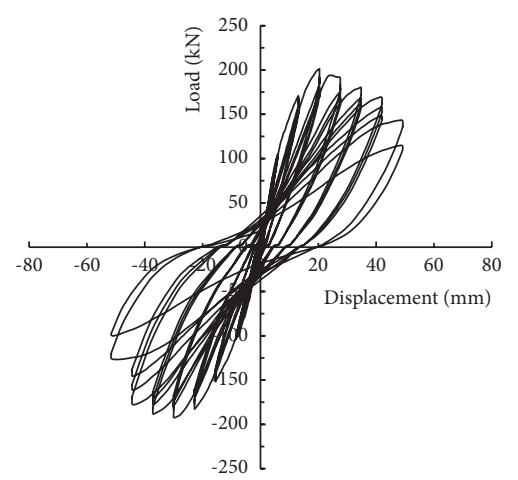

(e)

Figure 5: Hysteresis curves of specimens. (a) PTRC-1. (b) PURC-1. (c) PURC-2 and PURC-p3. (d) PURC-4.

specimens with posttensioned unbonded prestressed tendons, and the peak load of these specimens is increased by $5.97 \%, 7.53 \%, 12.59 \%$, and $2.86 \%$, respectively. It shows that the addition of posttensioned unbonded prestressed tendons can reduce the energy dissipation performance of concrete columns, but cannot significantly improve their bearing capacity.

(3) Hysteresis curves of PURC-2, PURC-1, and PURC-3 are compared. Under the same preloaded axial compression ratio of specimens, when the applied axial compression ratio increases from $0.05,0.15$, to 0.25 , the fullness of hysteresis curve becomes worse, the limit displacement becomes smaller, and the load after yield decreases faster. It indicates that the energy dissipation performance of posttensioned unbonded prestressed concrete columns becomes worse with the increase in the applied axial compression ratio.

(4) Hysteresis curves of PURC-1 and PURC-4 are compared. Under the same applied axial compression ratio of the specimen, when the preloaded axial compression ratio is 0.4 and 0.25 , the fullness of the hysteresis curve of PURC-4 is relatively good, and the limit displacements of PURC-1 and PURC-4 are similar. It indicates that the greater the preloaded axial compression ratio, the lower the energy consumption capacity of the specimen.
4.2. Skeleton Curves. Figure 6 shows skeleton curves of test columns. The skeleton curves of test columns are compared.

(1) By comparing skeleton curves of PTRC-1 and PURC-1, it is found that the rising section and falling section of the skeleton curve of PTRC-1 are steep, and the initial stiffness is large, while the falling section of the curve of PURC-1 is relatively gentle. This is because when the prestress is applied to the test column, the column is compacted, which is conducive to improve its stiffness. However, after the peak load, the concrete damage is accelerated and the bearing capacity is degraded rapidly due to the pressure of prestressed tendons.

(2) By comparing the skeleton curves of PURC-1, PURC-2, and PURC-3, it can be seen that the rising and falling sections of the skeleton curve of PURC-3 are the steepest, with the largest initial stiffness and the smallest ultimate displacement; the rising section and the falling section of the skeleton curve of the PURC- 2 are the most gentle, with the smallest initial stiffness and the largest limit displacement. It indicates that the greater the applied axial compression ratio, the smaller the ultimate displacement of the posttensioned unbonded prestressed concrete column and the more significant the ductility reduction.

(3) By comparing the skeleton curves of PURC-1 and PURC-4, it can be seen that the rising section of the 

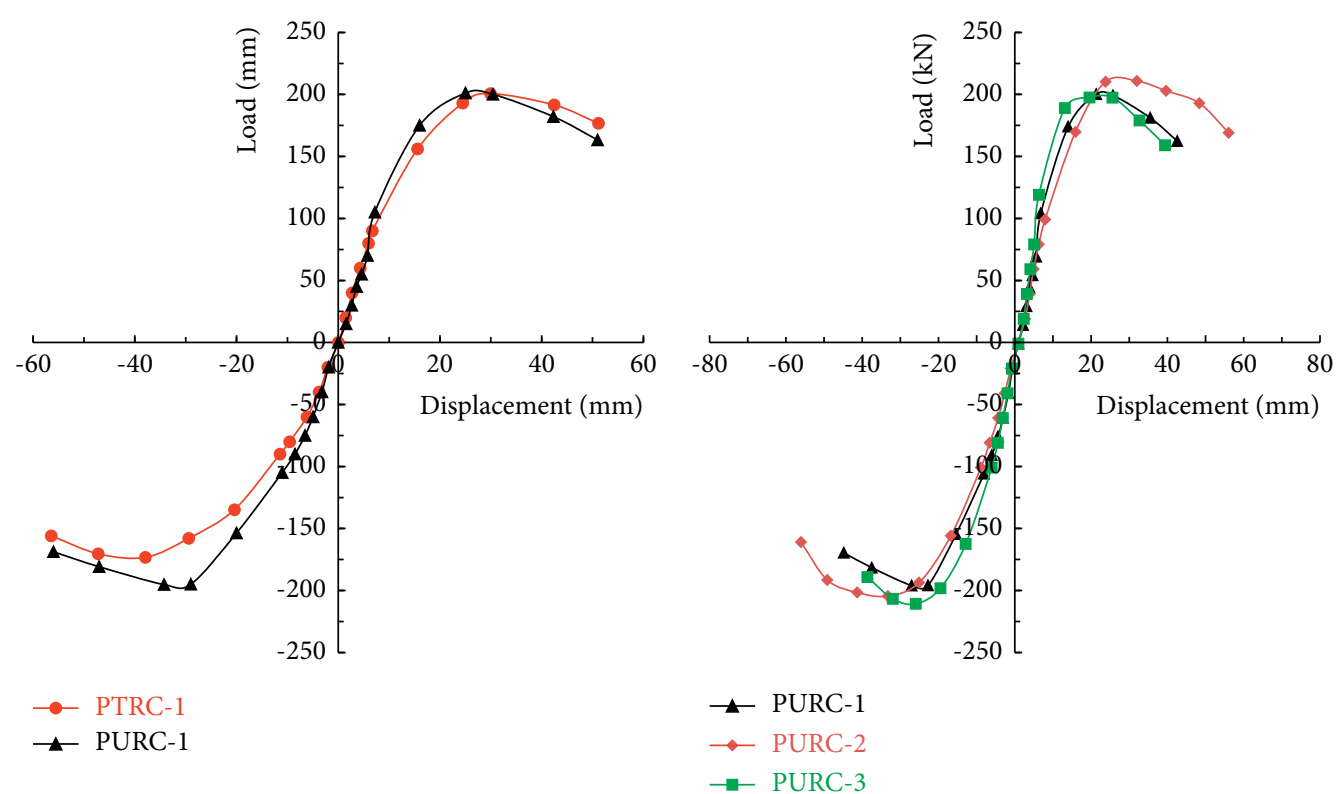

(a)

(b)

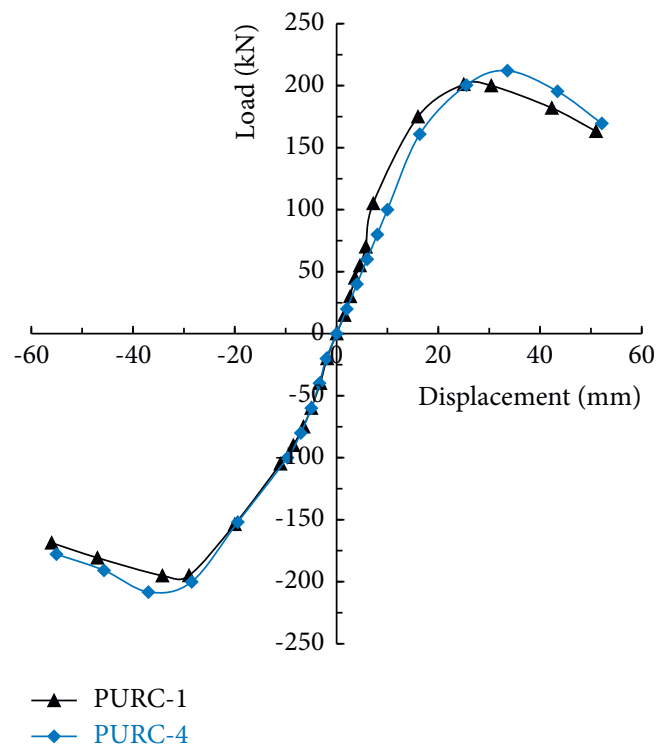

(c)

Figure 6: Skeleton curves of specimens. (a) PTRC-1 and PURC-1. (b) PURC-1, PURC-2, and PURC-3. (c) PURC-1 and PURC-4.

skeleton curve of PURC-4 is relatively gentle, the limit displacement is large, and its ductility is good.

4.3. Stiffness Degradation. Under the condition of pseudostatic test, the stiffness degradation characteristics of structures or members are usually characterized by loop stiffness:

$$
K_{j}=\frac{\sum_{i=1}^{n} V_{j}^{i}}{\sum_{i=1}^{n} \Delta_{j}^{i}}
$$

where $K_{j}$ is the stiffness under the $j$ th level load; $V_{j}^{i}$ is the average value of forward and reverse loads under the $j$ th level load at the $i$ th cycle; and $\Delta_{j}^{i}$ is the average value of forward and reverse displacement under the $j$ th level load at the $i$ th cycle. Figure 7 shows the skeleton curves of different specimens.

As shown in Figure 7, it is concluded that

(1) The stiffness degradation curves of all specimens are smooth without sudden change, indicating that the damage of posttensioned unbonded prestressed concrete develops stably under seismic load.

(2) Compared with ordinary reinforced concrete columns, the columns with posttensioned unbonded prestressed tendons present higher initial stiffness, but rapid stiffness loss after loading. It suggests that 


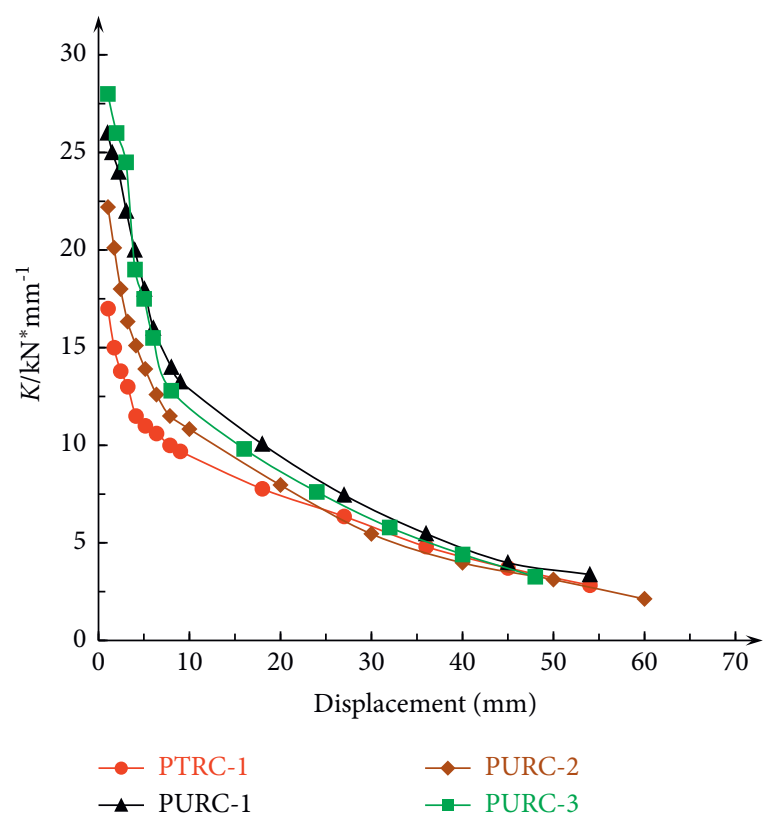

(a)

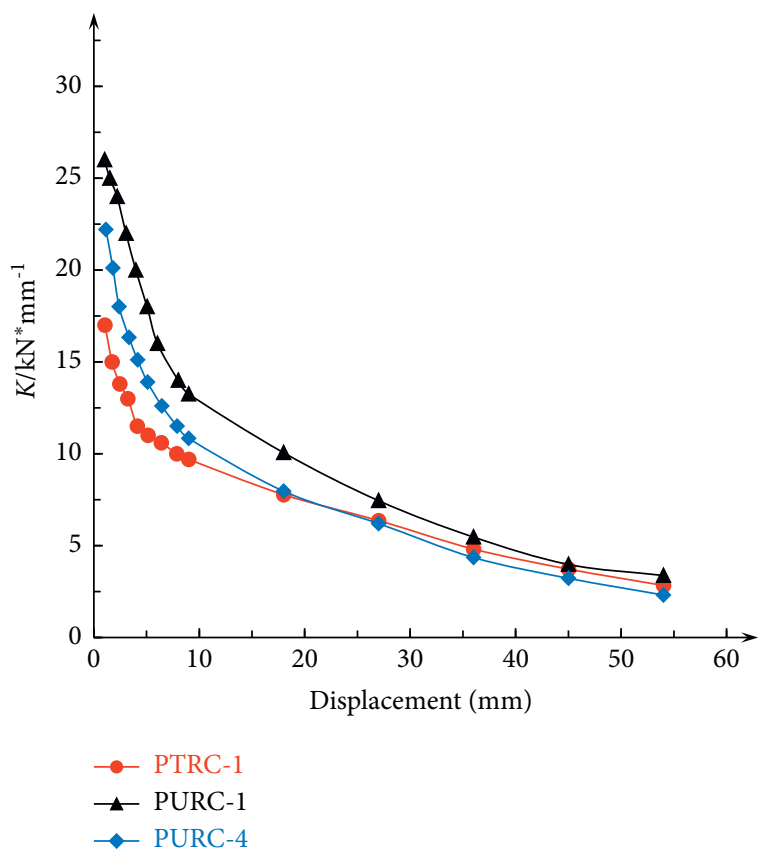

(b)

FIgURE 7: Stiffness degradation curves of specimens.

the prestressing can accelerate the damage of specimens.

(3) As shown in Figure 7(a), the effect of applied axial pressure ratio on stiffness degradation is significant. The greater the applied axial pressure ratio, the faster the stiffness degradation. As shown in Figure 7(b), the change in preloaded axial compression ratio before the specimen yielding has little effect on the stiffness degradation rate of the specimen; after the specimen yielding, the stiffness degradation of the specimen with a high preloaded axial compression ratio is accelerated. It shows that the greater the applied axial compression ratio, the faster the damage of the specimen and the faster the stiffness degradation. Besides, the preloaded axial compression ratio rarely affects the damage rate of the specimen before yielding, but accelerates the damage rate of the specimen after yielding and the stiffness degradation is accelerated.

\subsection{Bearing Capacity}

4.4.1. Test Value of Bearing Capacity. Tables 4 and 5 show the load, displacement, displacement angle, and displacement ductility coefficient of different characteristic points of the specimen. The yield displacement is obtained by the energy method [17], and the ultimate load and displacement are the corresponding load and displacement values when the load drops to $85 \%$ of the peak load. The experimental results show that

(1) By comparing the PTRC-1 with PURC-1-1 and PURC-1-4, it can be found that the yield displacement of concrete columns with unbonded prestressed tendons increases, while the addition of unbonded prestressed tendons rarely affects the peak load, peak displacement, ultimate load, and ultimate displacement. Compared with PTRC-1, the yield displacement of PURC- 1 and PURC-4 increases by $36.31 \%$ and $26.18 \%$, respectively. The three specimens enter the yield state at the displacement angle of $1 / 37-1 / 36$ and fail at the displacement angle of $1 /$ $22-1 / 21$. This is because for large eccentric compression members, the reinforcement in the tensile area first yields, and then, the concrete in the compression area is damaged by compression, but the existence of preload slows down the yield of reinforcement in the tensile area, resulting in the increase in yield load and displacement of the specimen; however, after the specimen yields, the prestressed tendons basically stop working. At this time, the specimen can be approximately equivalent to an ordinary reinforced concrete column. Therefore, the peak load, peak displacement, ultimate load, and ultimate displacement of PURC-1 and PURC-4 are not significantly different from those of PTRC-1.

(2) The test values of PURC-1, PURC-2, and PURC-3 are also analyzed. Compared with PURC-2, the yield load of PURC-1 and PURC-3 increases by $19.39 \%$ and $22.20 \%$, and their yield displacement decreases by $9.88 \%$ and $9.70 \%$; the peak load of PURC- 1 and PURC-3 increases by $2.64 \%$ and $11.63 \%$, and their peak displacement decreases by $13.43 \%$ and $25.30 \%$; the ultimate load of PURC-1 and PURC-3 increases by $3.71 \%$ and $10.19 \%$, and their ultimate displacement decreases by $12.57 \%$ and $17.52 \%$, respectively. 
TABLE 4: Ductility coefficients of the specimens.

\begin{tabular}{|c|c|c|c|c|c|c|c|c|c|}
\hline $\begin{array}{l}\text { Specimen } \\
\text { No. }\end{array}$ & $\begin{array}{l}\text { Loading } \\
\text { direction }\end{array}$ & $\begin{array}{c}\text { Yield } \\
\text { load } \\
P_{y} / \mathrm{kN} \\
\end{array}$ & $\begin{array}{c}\text { Yield } \\
\text { displacement } \\
\Delta_{y} / \mathrm{mm}\end{array}$ & $\begin{array}{c}\text { Peak } \\
\text { load } \\
P_{\mathrm{b}} / \mathrm{kN}\end{array}$ & $\begin{array}{c}\text { Peak } \\
\text { displacement } \\
\Delta_{\mathrm{b}} / \mathrm{mm} \\
\end{array}$ & $\begin{array}{c}\text { Ultimate } \\
\text { load } \\
P_{\mathrm{u}} / \mathrm{kN}\end{array}$ & $\begin{array}{c}\text { Ultimate } \\
\text { displacement } \\
\Delta_{\mathrm{u}} / \mathrm{mm}\end{array}$ & $\begin{array}{l}\text { Ductility } \\
\text { coefficient } \\
u=\Delta_{u} / \Delta_{y}\end{array}$ & $\begin{array}{c}\text { Ductility } \\
\text { coefficient } \\
\text { average }\end{array}$ \\
\hline \multirow{2}{*}{ PTRC-1 } & \multirow{2}{*}{$\begin{array}{c}\text { Forward } \\
\text { direction } \\
\text { Reverse } \\
\text { direction } \\
\end{array}$} & 168.29 & 11.22 & 200.71 & 29.92 & 170.60 & 51.16 & 4.56 & \multirow[b]{2}{*}{4.75} \\
\hline & & -160.80 & -12.07 & -173.20 & -32.92 & -147.22 & -59.52 & 4.93 & \\
\hline \multirow{2}{*}{ PURC-1 } & \multirow{2}{*}{$\begin{array}{c}\text { Forward } \\
\text { direction } \\
\text { Reverse } \\
\text { direction }\end{array}$} & 178.26 & 15.73 & 201.06 & 25.00 & 170.90 & 53.84 & 3.22 & \multirow{2}{*}{3.29} \\
\hline & & -188.98 & -16.02 & -195.19 & -30.24 & -165.91 & -56.94 & 3.35 & \\
\hline \multirow{2}{*}{ PURC-2 } & \multirow{2}{*}{$\begin{array}{c}\text { Forward } \\
\text { direction } \\
\text { Reverse } \\
\text { direction }\end{array}$} & 153.26 & 17.35 & 188.50 & 28.02 & 160.23 & 62.86 & 3.62 & \multirow{2}{*}{3.60} \\
\hline & & -154.33 & -17.89 & -193.57 & -35.85 & -164.53 & -63.83 & 3.57 & \\
\hline \multirow{2}{*}{ PURC-3 } & \multirow{2}{*}{$\begin{array}{c}\text { Forward } \\
\text { direction } \\
\text { Reverse } \\
\text { direction } \\
\end{array}$} & 189.97 & 15.22 & 211.16 & 22.82 & 179.47 & 53.53 & 2.94 & \multirow{2}{*}{2.92} \\
\hline & & -185.96 & -16.59 & -219.83 & -24.90 & -178.36 & -50.97 & 2.90 & \\
\hline \multirow{2}{*}{ PURC-4 } & $\begin{array}{l}\text { Forward } \\
\text { direction }\end{array}$ & 161.42 & 14.45 & 192.14 & 27.56 & 163.32 & 54.05 & 3.29 & \multirow{2}{*}{3.41} \\
\hline & $\begin{array}{l}\text { Reverse } \\
\text { direction }\end{array}$ & -163.77 & -14.94 & -192.46 & -34.99 & -163.59 & -59.57 & 3.52 & \\
\hline
\end{tabular}

TABLE 5: Average value of load and displacement angle of specimens.

\begin{tabular}{lcccccccc}
\hline $\begin{array}{l}\text { Specimen } \\
\text { number }\end{array}$ & $\begin{array}{c}\text { Yield } \\
\text { load } \\
P_{y} / \mathrm{kN}\end{array}$ & $\begin{array}{c}\text { Average yield } \\
\text { displacement } \\
\Delta_{y} / \mathrm{mm}\end{array}$ & $\theta_{y}=\Delta_{y} / H$ & $\begin{array}{c}\text { Average } \\
\text { peak load } \\
P_{b} / \mathrm{kN}\end{array}$ & $\begin{array}{c}\text { Average peak } \\
\text { displacement } \\
\Delta_{b} / \mathrm{mm}\end{array}$ & $\theta_{\mathrm{b}}=\Delta_{\mathrm{b}} / H$ & $\begin{array}{c}\text { Average } \\
\text { ultimate } \\
\text { load }\end{array}$ & $\begin{array}{c}\text { Average } \\
\text { ultimate } \\
\text { displacement } \\
P_{u} / \mathrm{kN}\end{array}$ \\
\hline PTRC-1 & 164.55 & 11.65 & $1 / 99$ & 186.96 & 31.42 & $1 / 37$ & 158.91 & 55.34 \\
PURC-1 & 183.62 & 15.88 & $1 / 72$ & 198.13 & 27.62 & $1 / 42$ & 168.41 & 55.39 \\
PURC-2 & 153.80 & 17.62 & $1 / 65$ & 193.04 & 31.94 & $1 / 36$ & 162.38 & 63.35 \\
PURC-3 & 187.97 & 15.91 & $1 / 68$ & 215.50 & 23.86 & $1 / 48$ & 178.92 & 52.25 \\
PURC-4 & 162.60 & 14.70 & $1 / 69$ & 192.30 & 31.28 & $1 / 37$ & 163.46 & 56.81 \\
\hline
\end{tabular}

It shows that under the same preloaded axial compression ratio, the greater the applied axial compression ratio, the greater the yield load, peak load, and ultimate load, and the smaller the yield displacement, peak displacement, and ultimate displacement.

4.4.2. Bearing Capacity Attenuation. Under the control of displacement amplitude at the same level, the bearing capacity of the specimen after yielding decreases with the increase in loading times, which is called bearing capacity attenuation. The bearing capacity attenuation $\Phi_{i}$ can be expressed as follows:

$$
\Phi_{i}=\frac{P_{j-i}}{P_{j-1}},
$$

where $P_{j-i}$ is the peak load value of the $i$ th cycle under the $j$ th level displacement amplitude; $P_{j-1}$ is the peak load value of the first cycle under the $j$ th level displacement amplitude.
Figure 8 shows the strength attenuation of different specimens. It can be found that:

(1) The strength attenuation of each specimen increases with the increase in loading displacement; during the same level displacement loading cycle, the attenuation degree of the third loading is less than that of the second loading.

(2) The average attenuation rates of PURC-1, PTRC-1, PTRC-2, PTRC-3, and PTRC-4 before failure are $4.70 \%, 6.16 \%, 5.98 \%, 7.13 \%$, and $7.46 \%$; their maximum strength attenuation rates are $10.05 \%, 10.23 \%$, $10.14 \%, 10.21 \%$, and $11.93 \%$, and the corresponding displacement angles are $1 / 23,1 / 29,1 / 26,1 / 26$, and $1 /$ 39 , respectively. It can be found that the strength attenuation of prestressed reinforced concrete columns is faster than that of the ordinary columns. Comparing PURC-1 and PURC-4, it can be found that the average attenuation rate of PURC-4 is $21.10 \%$ higher than that of PURC-1, and the maximum attenuation rate of PURC- 4 is $16.62 \%$ higher 


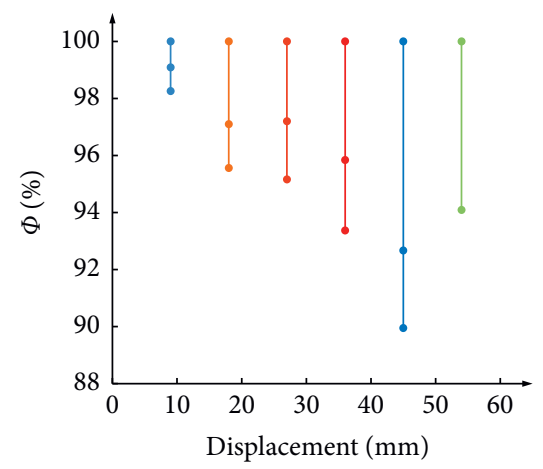

(a)

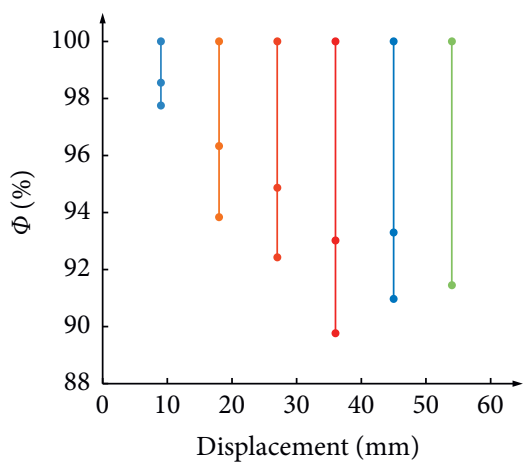

(b)

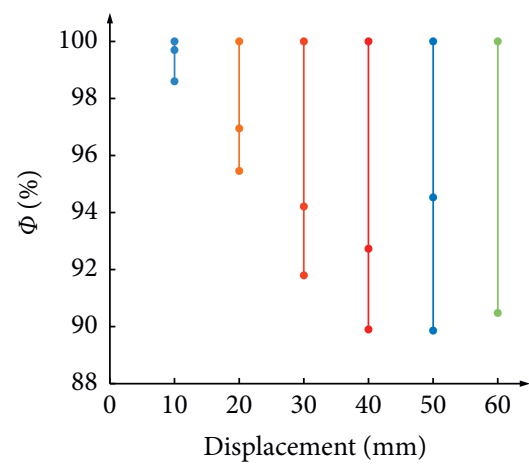

(c)

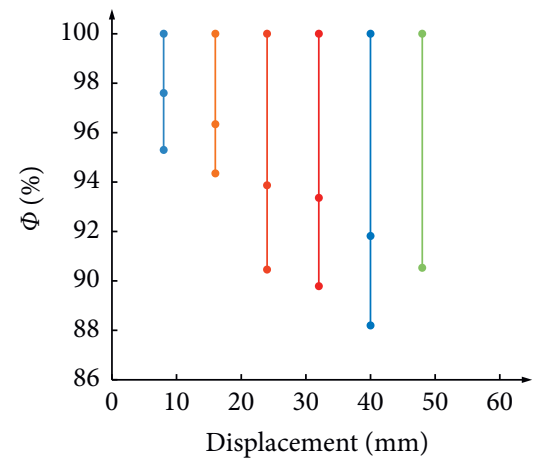

(d)

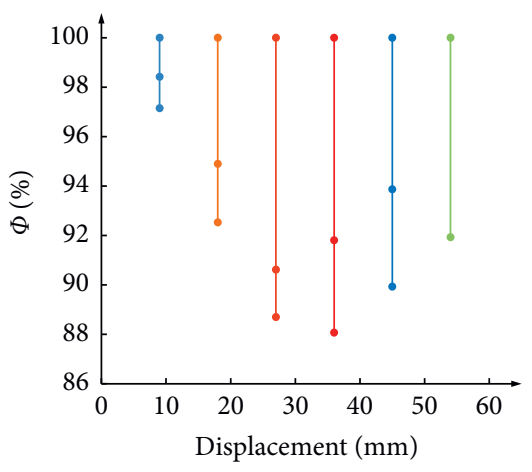

(e)

Figure 8: Strength attenuation of each specimen. (a) PTRC-1. (b) PURC-1. (c) PURC-2. (d) PURC-3. (e) PURC-4.

than that of PURC-1. It indicates that for the specimen with a small preloaded axial compression ratio, the faster the strength attenuation, the smaller the maximum strength attenuation rate. This is because during the loading process, with the increase in displacement, the deformation of prestressed tendons increases, and the preloaded axial pressure gradually increases; for the specimens with a small preloaded axial compression ratio, the prestressed tendons quit work in the later stage. By comparing PURC-1, PURC-2, and PURC-3, it can be found that the greater the applied axial compression ratio, the greater the strength attenuation rate and maximum amplitude of the specimen.

4.5. Ductility and Energy Dissipation. Ductility refers to the deformation capacity of a certain section of a structure or component from the beginning of yield to the maximum bearing capacity. The calculation equation of ductility is as follows:

$$
u=\frac{\Delta_{u}}{\Delta_{y}},
$$

where $u$ is ductility coefficient; $\Delta_{u}$ is the ultimate displacement of the structure or member under load; and $\Delta_{y}$ is the yield displacement of the structure or member under load. The yield displacement is determined by the energy method. Based on the test data and calculation results, the ductility coefficient and displacement angle of each test column are obtained, as shown in Tables 4 and 5, Table 4 shows the ductility coefficients of the specimens, and Table 5 shows the average value of load and displacement angle of specimens. The energy dissipation performance can be measured by the equivalent damping coefficient $h_{\mathrm{e}}$, and the calculation results are shown in Figure 9.

As shown in Tables 4 and 5, the ductility of the column with unbonded prestressed tendons is worse than that of an ordinary reinforced concrete column. Through the data comparison of PURC-1, PURC-2, and PURC-3, it can be found that the greater the applied axial compression ratio, the smaller the displacement ductility coefficient of the test column; through the data comparison of PURC-1 and PURC-4, it can be found that the larger the preloaded axial compression ratio, the smaller the displacement ductility coefficient of the test column.

As shown in Figure 9, the energy dissipation coefficient of the column with unbonded prestressed tendons is less than that of ordinary reinforced concrete column. It indicates that the addition of prestressed tendons can lead to the deterioration of the energy dissipation performance of the member. Regardless of the axial compression ratio, the greater the loading displacement of each test column, the greater the equivalent damping coefficient; the larger the applied axial compression ratio and preloaded axial compression ratio of each test column, the smaller the equivalent damping coefficient. It shows that the increase in the applied axial compression ratio and the preloaded axial compression ratio leads to the deterioration of the energy dissipation capacity of the column. 


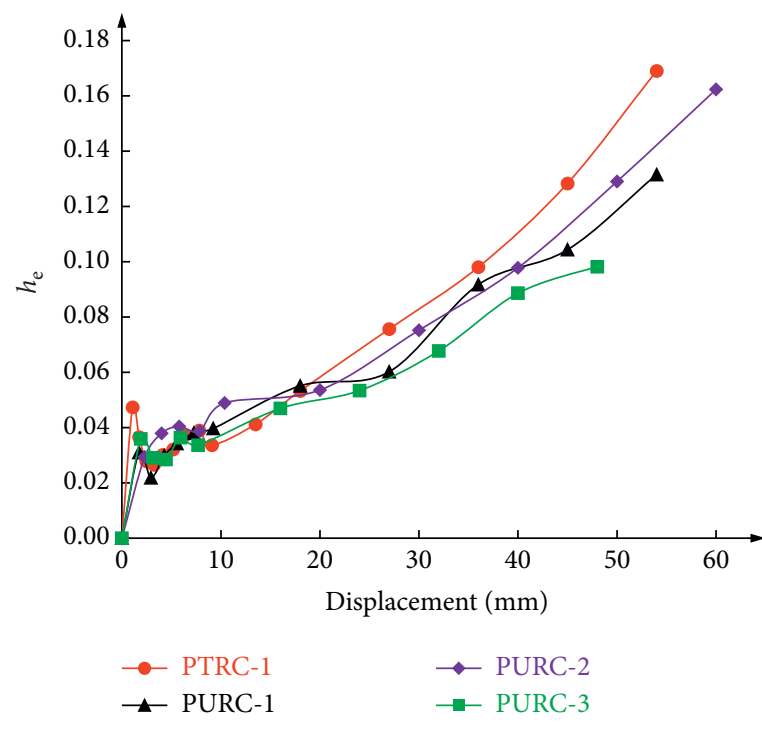

(a)

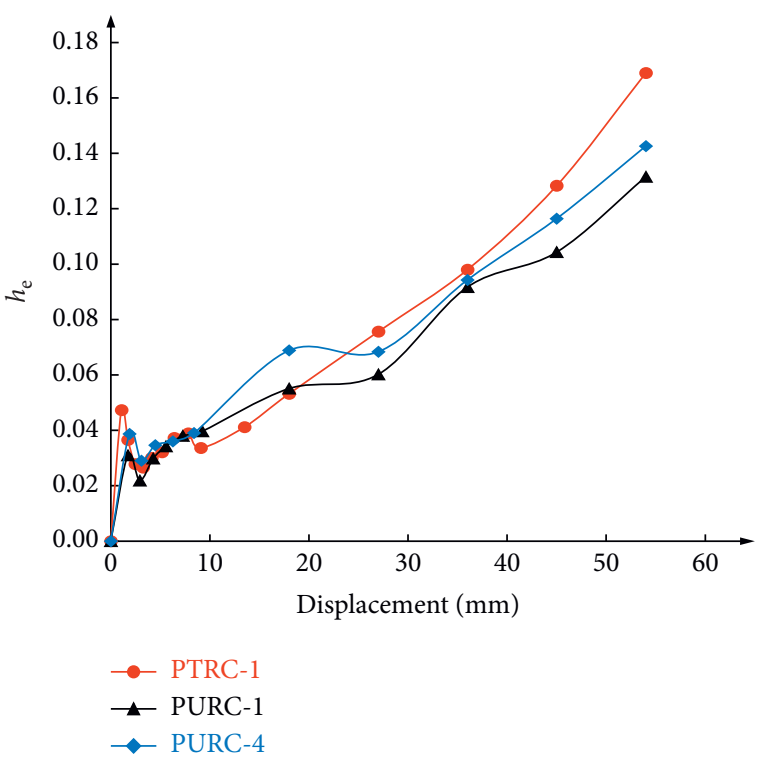

(b)

Figure 9: Comparison of equivalent damping coefficients.

4.6. Self-Centering Performance. The self-centering performance of a structure or member refers to its recovery performance to the initial state after applying the load. To intuitively reflect the self-centering performance of test columns, the self-centering capability coefficient $\gamma$ is used, and it can be calculated as follows:

$$
\gamma=1-\frac{\Delta_{r}}{\Delta_{m}},
$$

where $\gamma$ is the self-centering capability coefficient; $\Delta_{r}$ is the residual displacement of the structure or member after the load; and $\Delta_{m}$ is the maximum displacement of the structure or member under load. Figure 10 shows the changing curve of the self-centering capability coefficient of test columns.

As shown in Figure 10, it is concluded that

(1) The concrete column with unbonded prestressed tendons has a large self-centering capability coefficient and strong self-centering performance, which can reduce the residual displacement of the test column. When the loading displacement is $+54 \mathrm{~mm}$, the residual displacement of PURC-1 is $34.10 \%$ less than that of PTRC-1, and the reduction capacity coefficient of PURC-1 is 1.3 times larger than that of PTRC-1.

(2) When the displacement is small, the self-centering capability coefficient of the specimen is relatively stable with a small changing trend, and the selfcentering capability curve is basically parallel to the $x$-axis. When the loading displacement increases, the self-centering capability coefficient of the test column decreases gradually. The greater the loading displacement, the faster the reduction in the selfcentering capability coefficient.

(3) At the beginning of loading, the larger the applied axial pressure ratio of the test column, the larger the initial self-centering capability coefficient. However, with the increase in the loading displacement, the decline rate of the self-centering capability coefficient accelerates, the changing curve of the self-centering capability coefficient becomes steeper and steeper, and the self-centering capability coefficient of the column with a large applied axial pressure ratio is gradually smaller than that of the column with a small applied axial pressure ratio. It shows that the excessive applied axial compression ratio is not conducive to maintain the self-centering performance of prestressed concrete columns after damage. This is because the restoring force of the test column is provided by the prestressed tendons and the main reinforcement. The greater the applied axial pressure ratio, the more work the restoring force needs to overcome the axial pressure in the process of specimen recovery.

(4) The larger the preloaded axial compression ratio, the smaller the residual displacement of the test column, and the larger the self-centering capability coefficient. This is because the greater the prestress, the greater the restoring force provided. Besides, the preloaded axial compression ratio has little effect on the reduction rate of the self-centering coefficient of the test column. 


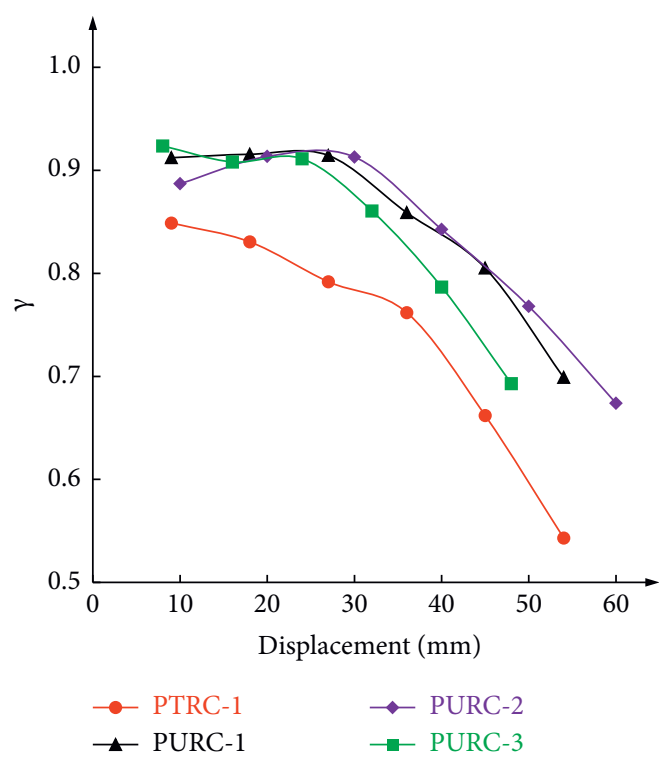

(a)

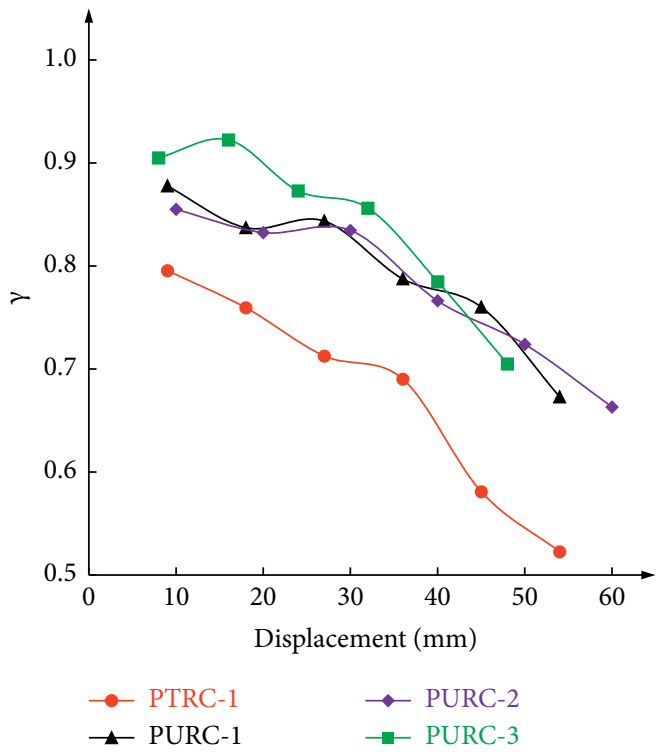

(c)

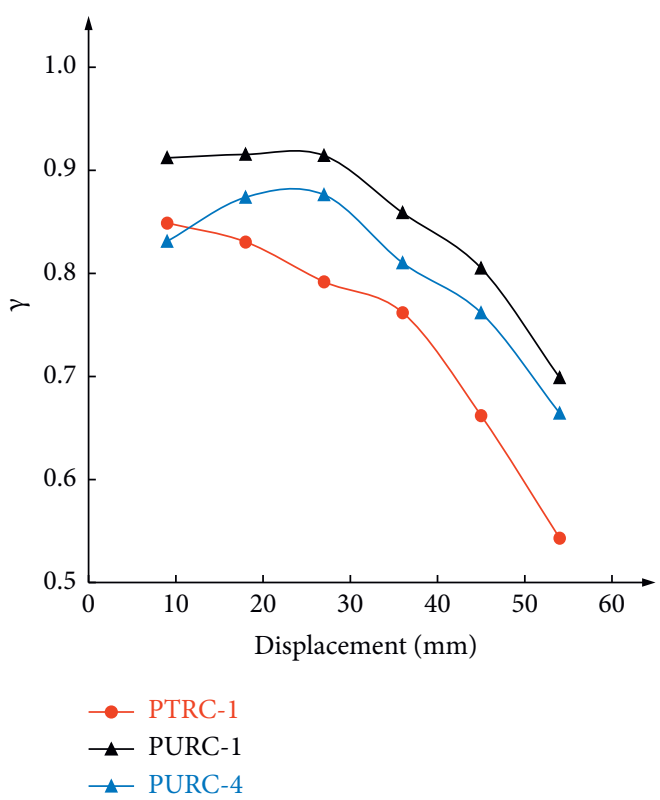

(b)

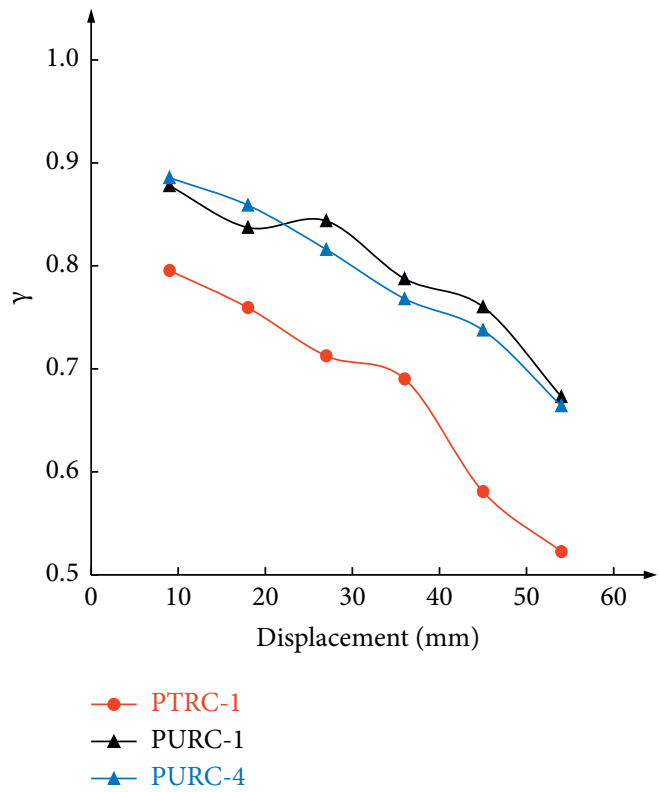

(d)

FIGURE 10: Self-centering capability coefficient of specimens. Note. (a) and (b) present the self-centering capability coefficients of specimens under the forward loading; $(c)$ and (d) present the self-centering capability coefficients of specimens under the reverse loading.

\section{Conclusion}

In this test, the low-cycle repeated loading tests were conducted on one ordinary reinforced concrete column and four reinforced concrete columns with posttensioned unbonded prestressed tendons under different axial compression ratios. The conclusions are obtained as follows:

(1) Adding posttensioned unbonded prestressed tendons to ordinary reinforced concrete columns can lead to poor energy dissipation performance, but it can effectively improve the self-centering performance of the test columns and reduce the residual displacement of the columns.

(2) Axial compression ratio is an important factor affecting the seismic performance of test columns. With the increase in the applied axial compression ratio, the bearing capacity and initial stiffness of the column increase, but the ductility and energy dissipation performance become worse, and the stiffness and bearing capacity decay faster. The increase in the preloaded axial compression ratio can deteriorate the ductility and energy dissipation 
performance of columns, but rarely affects the bearing capacity of columns. Besides, the increase in the preloaded axial compression ratio can reduce the attenuation rate of bearing capacity.

(3) The elastic displacement angle of each test column is between $1 / 21$ and $1 / 18$, which meets the design requirement that the displacement angle between elastic-plastic layers is not less than 1/50 under rare earthquake action. It indicates that the posttensioned unbonded prestressed concrete column has good collapse resistance.

(4) The average strength attenuation rate of each test column under all levels of loading displacement amplitude is not more than $8 \%$, and the maximum strength attenuation rate is not more than $12 \%$. It indicates that the posttensioned unbonded prestressed concrete column has good seismic bearing capacity under earthquake.

(5) The axial compression ratio has an important influence on the self-centering performance of posttensioned unbonded prestressed concrete columns. The larger the applied axial pressure ratio, the better the initial self-centering performance of the column, but the faster the self-centering performance attenuation in the later stage of loading, the worse the self-centering performance. The greater the preloaded axial compression ratio, the better the selfcentering performance of the column. Besides, the preloaded axial compression ratio has no significant effect on the attenuation rate of self-centering performance.

\section{Data Availability}

The data used to support the findings of this study are included within the article.

\section{Conflicts of Interest}

The authors declare that they have no conflicts of interest.

\section{Acknowledgments}

The work in this study was supported by the Natural Science Foundation of the Jiangsu Higher Education Institutions of China (20KJB560012). The authors would like to acknowledge the support of the organizations for providing photographs and advice.

\section{References}

[1] J. F. Jia, B. Wei, and J. P. Ou, “Test for seismic performance of prefabricated self-centering bridge piers with external replaceable energy dissipator," Journal of Vibration and Shock, vol. 40, no. 5, pp. 154-162, 2021.

[2] E. Xiong, K. Zu, J. Wang, and Q. Zhang, "Seismic performance analysis of self-centering concentrically braced steel frame structures," World Earthquake Engineering, vol. 36, no. 3, pp. 69-79, 2020.
[3] J. Erochko, C. Christopoulos, and R. Tremblay, "Design and testing of an enhanced-elongation telescoping self-centering energy-dissipative brace," Journal of Structural Engineering, vol. 141, no. 6, 2015.

[4] C.-C. Chou, W.-J. Tsai, and P.-T. Chung, "Development and validation tests of a dual-core self-centering sandwiched buckling-restrained brace (SC-SBRB) for seismic resistance," Engineering Structures, vol. 121, pp. 30-41, 2016.

[5] D. J. Miller, L. A. Fahnestock, and M. R. Eatherton, "Development and experimental validation of a nickel-titanium shape memory alloy self-centering buckling-restrained brace," Engineering Structures, vol. 40, pp. 288-298, 2012.

[6] Z. Zhou, Q. Xie, X. C. Lei, X. He, and S. Meng, "Experimental investigation of the hysteresis performance of dual-tube selfcentering buckling-restrained braces with composite tendons," Journal of Composites for Construction, vol. 19, no. 6, Article ID 4015011, 2015.

[7] C. Fang, M. C. H. Yam, T.-M. Chan, W. Wang, X. Yang, and $\mathrm{X}$. Lin, "A study of hybrid self-centring connections equipped with shape memory alloy washers and bolts," Engineering Structures, vol. 164, pp. 155-168, 2018.

[8] H. Y. Luo, Q. Li, and Z. B. Wang, "Experimental study on restoring performance of unbonded partially prestressed concrete columns," China Concrete and Cement Products, vol. 7, pp. 44-48, 2013.

[9] L. Lu, Y. L. Ye, and W. Q. Xia, "Study on the seismic performance of a 3D external prestressed self-centering reinforced concrete frame by shaking test," China Civil Engineering Journal, vol. 53, no. S2, pp. 68-73+108, 2020.

[10] H. Qian, J. t. Xu, and J. t. Zhu, "Numerical simulation of mechanical behaviors of the innovative self-centering coupling beam damper," World Earthquake Engineering, vol. 36, no. 4, pp. 121-129, 2020.

[11] D. Roke, R. Sause, J. M. Ricles, and N. Gonner, "Design concepts for damage-free seismic-resistant self-centering steel concentrically-braced frames," in Proceedings of the 14th World Conference on Earthquake Engineering, pp. 1-10, Beijing, China, October 2009.

[12] H. Y. Luo, Research on the Influence of the Degree of Prestress to Re-centering Behavior of Unbonded Partially Prestressed concrete Columns, Yangzhou University, Yangzhou, China, 2008.

[13] Y. M. Yang, P. Yang, and H. J. Gao, "Experimental study on the seismic behavior of self-centering RC frame column base joints under different axial compressive ratios," Journal of Tianjin University, vol. 53, no. 5, pp. 542-550, 2020.

[14] F. M. Li, Effect of Steel Strands Corrosion on Prestressed concrete Structures under Chloride Environment, China University of Mining and Technology, Beijing, China, 2008.

[15] China University of Mining and Technology, A Tensioning Support Foot Device: 200720035651, China University of Mining and Technology, Xuzhou, China, 2008.

[16] China Academy of Building Research, Specification For Seismic Test of Buildings: JGJ/T101-2015, China Architecture \& Building Press, Beijin, China, 2015.

[17] J. Yan, Z. L. Li, and G. Zuo, "An experimental study on the seismic performance of welded closed stirrup concrete columns," Journal of Vibration and Shock, vol. 37, no. 24, pp. 148-157+171, 2018. 